\title{
Hidden Foreign Body in the Orbit and Cavernous Sinus Masquerading Strabismus
}

\author{
RK Rauniyar ${ }^{1}$, B Badhu' ${ }^{2}$ U Sharma ${ }^{3}$, A Panda $^{2}$ \\ ${ }^{1}$ Department of Radio-diagnosis and Imaging \& ${ }^{2}$ Ophthalmology, BPKIHS, Dharan Nepal \\ ${ }^{3}$ Department of Radio-diagnosis and Imaging, B \& B Teaching Hospital, Lalitpur, Nepal
}

\begin{abstract}
Intraorbital foreign bodies with intracranial extension can produce both visual and life threatening problems. The present report highlights a 9 year old patient who sustained an ocular trauma following a fall from a height, but refused to admit the same and reported to the ophthalmologist late when complicated symptoms such as deviation of eye ball with mild proptosis appeared. The authors described the value of accurate history taking and complete radiological evaluation for these traumatised eyes. Clinical examination and routine radiological study may not be sufficient to detect these foreign bodies.
\end{abstract}

Keywords: Foreign body, cavernous sinus, proptosis.

\section{Introduction}

Orbito-cranial penetration by foreign body posseses problems in diagnosis and management ${ }^{1}$. Detection of hidden foreign body by clinical examination is extremely difficult. Most of the time simple radiological examination of the orbit fails to identify these foreign bodies. Computerised Tomography (CT) scan could be a valuable aid as it provides a method of visualizing tissues and objects of different densities ${ }^{1-3}$. This report highlights a patient with confusing clinical history and findings but with radiological diagnosis of transorbital penetrating injury with retained nonmetalic foreign body.

Correspondence to: Dr. R. K. Rauniyar

Professor and Head,

Department of Radiodiagnosis and Imaging

BPKIHS, Dharan Nepal

E-mail: rauniyar99@yahoo.com
Diagnostic importance of CT scanning in such patients is emphasized.

\section{Case Report}

A 9 year old girl presented to out patient department of Ophthalmology at B P Koirala Institute of Health Sciences (BPKIHS) with complaint of sudden inward deviation of right eye with mild proptosis and occasional double vision over 2 weeks. Parents say, the child was apparently alright till 3 weeks ago when she developed the prominence of right eye, and inward deviation of same eye for 2 weeks. They consulted a general physician near the village who referred the child to the ophthalmologist for management of strabismus. 
The clinical examination revealed a normal healthy girl child with right esotropia $40^{\circ}$ and restriction of ocular motility in lateral gaze. Rest of the movements was full. The eye was not coming to central position by the cover test but it was possible by forced duction test (Negative FDT). No palpable mass could be detected. Visual acuity was $6 / 6$ in both eyes. No apparent site of wound entry could be visualised in conjunctiva, cornea, limbus or sclera. Slit lamp examination of the anterior segment failed to demonstrate any anterior segment abnormalities. Pupils were briskly reactive without a relative afferent pupillary defect. On ophthalmoscopy, the fundi were within normal limit. Intraocular pressure in right eye by Applanation tonometer was 24 and $17 \mathrm{~mm}$ in right \& left eye respectively. The drainage angle appeared normal on gonioscopy. A clinical diagnosis of right VI nerve palsy with secondary glaucoma was made. On repeated questioning the child admitted that she fell down from a height with the face down position on a bush 4 weeks ago. Following the episode, there was blood tinse discharge from right eye at medial canthal region without any visual alteration.

On the basis of clinical findings and history of trauma the diagnosis of Traumatic VI nerve palsy with secondary glaucoma right rye was made. Radiological investigations were adviced to rule out any hidden foreign body and topical timolol maleate drop $0.5 \%$ BD was started.

Plain X-ray of orbit showed no foreign body but CT scan revealed engorged cavernous sinus with an elongated nonmetalic foreign body of length $10 \mathrm{~cm} \times 0.5 \mathrm{~cm}$ in the right orbit in infero-medial part passing through optic canal into cavernous sinus (Fig. 1, 2 and 3). Removal of foreign body was advised and the patient was referred to the neurosurgeon. Thereafter, the patient did not report to us for follow up.

\section{Discussion}

There have been several reports on retained orbitocranial foreign body in the orbit in neurosurgical literature ${ }^{1-5}$. However, there is a scanty report in ophthalmic literature to highlight its importance ${ }^{6-8}$. The mortality rate of penetrating orbital injuries with intracranial involvement is twofold than those associated with cranial wounds at other sites 9 . Retention of ultra orbital foreign bodies besides producing cranial nerve injury could be a cause of proptosis due to mechanical push. The potential risk of such foreign bodies include intracranial infection., aneurysms, haematoma, intraventricular hemorrhage, brain stem injury, carotid cavernous fistula etc ${ }^{10}$. Moreover, chances of

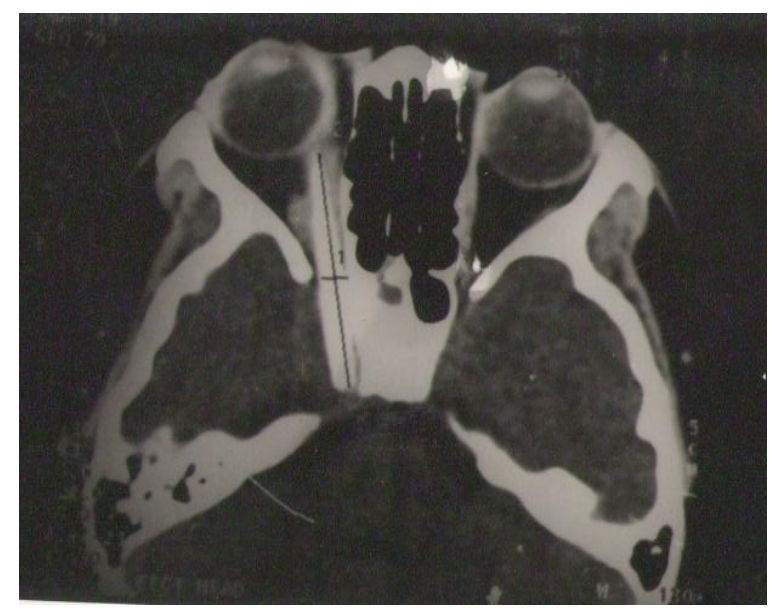

Figure 1: Plain axial CT scan of orbit showing long elongated foreign body in right orbit passing through optic foramen in to cavernous sinus.

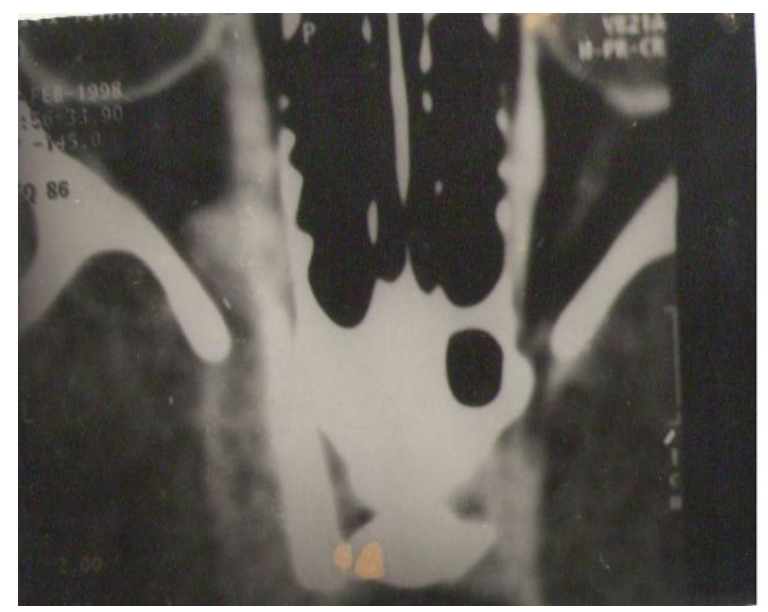

Figure 2: Enlarged view of engorged right cavernous sinus with foreign body. 
development of siderosis, chalcosis do exist depending upon the nature of the foreign bodies. The asymptomatic foreign body such as glass should be left behind and to be followed up. However, considering the risk of inflammation and infection leading to orbital cellulitis, abscess, (which could be fatal) more attention should be paid to the organic foreign bodies and their removal is mandatory. Our report is partially concurrent with that of literature that the penetrating orbital injuries occur more often through the lower orbital region due to least anatomical protection ${ }^{11}$ as the foreign body was lodged medially in our patient. However,

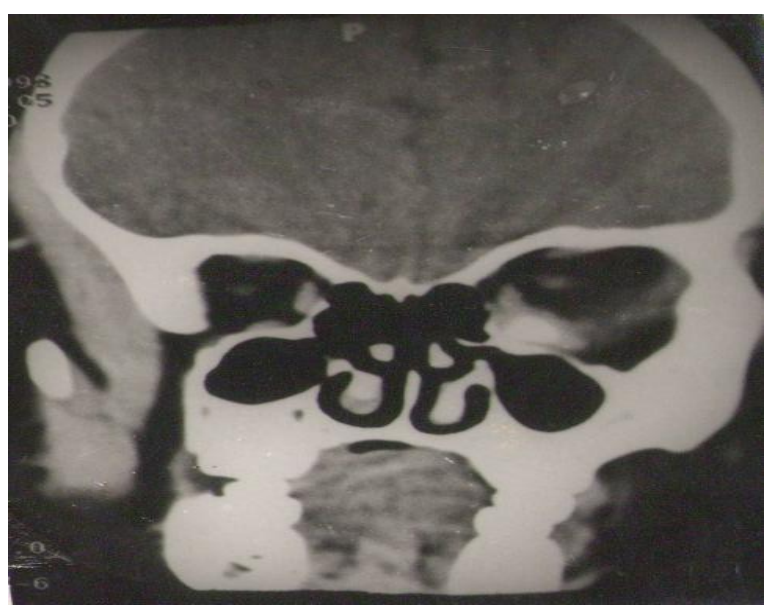

Figure 3: Plain coronal CT scan showing foreign body in infero-medial part of orbit.

not much could be commented on this issue due to nonvisualisation of the external wound entry. The patient under report is interesting firstly for its unusual presentation with vision threatening complication and secondly, presence of $10 \mathrm{~cm} \times 0.5 \mathrm{~cm}$ long slender foreign body without any external sign of wound entry which was not reported earlier. Moreover, it has not caused any bony destruction.

Management of such foreign bodies varies depending upon the nature of the foreign bodies and the complications they produce. The tendency of the lodgement of foreign body towards apex due to the horizontal pyramidal shape of the orbit and further advancement into the intracranial cavity through the optic fornn and superior orbital fissure is well known ${ }^{10}$. Penetration of foreign body through superior orbital fissure is rare and reported only in $10 \%$ of cases of intracranial penetration ${ }^{12}$. Further, penetration of such foreign bodies without bone fracture suggests the wound entry parallel to the orbital roof ${ }^{13}$. We in our patient presume that the foreign body has pierced from inferomedial part of the orbit and lying at the medial wall but reaching upto the apex. As the same was lying parallel to the medial wall no bony destruction has occured. Similarly foreign body was observed medially, clinically detected VI nerve palsy could be due to the compression by the foreign body rather than injury as the nerves were lying lateral to the foreign body.

In summary, the reported patient illustrates a serious feature of penetrating injury of the orbit that prompted an immediate CT scan. Raised intraocular pressure, proptosis and strabismus were misleading factors to suspect trauma. However, presence of $6^{\text {th }}$ nerve palsy provided the clue for trauma and the patient was interrogated. Thus, ophthalmologists should be aware of potential risk of retained orbitocranial foreign body without signs of visible penetration. A complete history taking is mandatory and prompt referral to neurosurgeons is essential to minimize the fatal outcomes both for life and vision.

\section{References}

1. Zanella FE, Modder U, Kirchhof B. Computed Tomography of the orbit. ROFO Fortschar Geb Rontgenstr Nuklearmed 1985;142:670-4

2. Kasamo S, Asakura T, Kusumoto $\mathrm{K}$ et al. Transorbital penetrating brain injury. No shinkei Geka. 1992;20:433-8 
3. Kahler RJ, Tomlinson FH, Eisen DP, Masel JP. Orbitocranial penetration byafern.NeurosurgerY 1998;42:13703

4. Green KA, Dickman CA, Smith KA et al. Self inflicted orbital and intracranial injury with retained foreign body. Surg Neurol 1993; 40:499-503.

5. Jarrahy R, cha ST. shahinian HK. J. Retain foreign body in orbit and cav.sinus. Craniofac surg. 2001, 12:82-86.

6. Vander JF, Nelson CC. Penetrating orbital injury with cavernous sinus involvement. Ophthalmic surg. 1988; 9:328-30.

7. Alexandrakis 0, Davis JL. Intracranial penetrating orbital injury. Ophthalmic surg. Lasers. 2000; 31:61-63.

8. Liguori G, Cioffi M, Sebastiani A. Ocular and cerebral trauma in nonaccidental injury in infancy. Br. I. ophthalmol 1997; 81(4):333

9. Nasr AM, Naik BG, Fleming JC et al penetrating orbitàl injury with organic foreign bodies. Ophthalmology 1999; 106:523-532.

10. Espillat A, Enzer Y, Lipsky S. Intra orbital metallic foreign body. Arch ophthalmol. 1998; 116:824-825.

11. Hansen JE, Gudeman SK, Holgate RC, Saunders RA. Penetrating intracranial wood wounds. Clinical limitations of CT. J. Neuro surg.1988; 68:752-756.

12. Braun J, Gdal-On M, Borovich B, Guilburd JN. Traumatic carotid aneurysm secondary to carotid sinus penetration by wood. CT features. J. Comput. Assit. Tomogr 1987;11:525528

13. Kasamo S, Asakura T, Kusumoto K et al. Transorbital penetrating brain injury. No Shinkei Geka. 1992;20:433-438 